\title{
Cracks in Doctoral STEM Mentoring Relationships: Students' Perceptions
}

\author{
Anna Sanczyk, Lisa R. Merriweather, Cathy D. Howell, Niesha Douglas \\ University of North Carolina at Charlotte \\ USA
}

\begin{abstract}
The United States has continued to lag behind similarly positioned nation-states in areas of science, technology, engineering, and mathematics (STEM). These are areas where a significant lack of equal racial representation exists. Recently there has been a push to explore racial underrepresentation. Mentoring is key for academic success in higher education, especially for women and underrepresented minority students in STEM doctoral programs. This article provides an account of mentoring relationships between doctoral students studying in STEM programs at a predominately white university (PWI) in the southeastern part of the United States and their doctoral faculty mentors. The qualitative research inquiry included focus groups with twenty-five students and individual interviews with nine underrepresented minority students studying within various STEM programs. Data were analyzed using an inductive, constant comparative process. The findings revealed cracks within the mentoring relationships experienced by STEM doctoral students that related to negligence, being misunderstood, and marginalization. These findings point to a critical need for faculty mentor training that prioritizes culturally responsive mentoring knowledge, skills, and dispositions in graduate STEM education.
\end{abstract}

\section{Introduction}

Universities across the United States lack equitable representation of underrepresented minorities (URM) within doctoral student populations in STEM programs. Neither the faculty nor the student population resemble the increasing diversity of the United States population [8]. The National Science Foundation [14] reports that women and minorities are underrepresented in achieving doctoral STEM related degrees. Scholars have explored a wide range of issues that may contribute to underrepresentation of women and minorities, but many emphasize the importance of support networks created by mentors, who can contribute to reducing the diversity gap in STEM graduate programs [7] [10]. Research illustrates that minority students experience racism, discrimination, and microaggressions during graduate school matriculation, especially in the STEM programs [10] [11] and women and minority students are more likely to face social, cultural, and intellectual isolation and neglect in their departments [17]. In view of such complex issues, this qualitative research study engaged STEM doctoral students in critical dialogue and reflection on their perceptions about their mentoring relationships.

\section{Literature Review}

Scholars have engaged in defining and exploring mentoring relationships. Mentoring serves end goals, such as academic and career advancement, involving providing support for meeting professional or academic goals. The support may be in the guise of career advice, professional networking and sponsorship, and professional knowledge sharing. Mentorships ideally extend beyond instrumental support, unidirectional transactional deposits of procedural knowledge about academic course selection or navigation through an academic field of study. Mentorships instead should provide psychosocial support through the creation of opportunities for relationships that are more dynamic, multidimensional, and bi-directional. Instrumental mentoring refers to offering professional development while the psychosocial refers to providing more emotional caring [19]. Both instrumental and psychosocial mentoring are crucial for graduate STEM students to thrive in doctoral programs [20], but most mentorships rarely move beyond the instrumental.

Mentoring relationships vary in both depth and duration but tend in general to be more holistic as well as supportive when they are effective. Effective mentorships have beneficial outcomes which include increased academic performance [2], productivity [19], persistence [19], career advancement [3], and development of a science identity [1]. Effective mentors connect students to career resources and research activities, and such networking opportunities create a mutually benefiting space for developing STEM students' confidence, independence, and 
dedication [10] which lead to psychosocial benefits, such as increased self-esteem, self-efficacy, and selfconfidence. For the purpose of this study, mentoring is an essential part of graduate student success and is defined as a relationship in which an experienced faculty is dedicated to providing developmental support to a doctoral student.

A definition of mentoring can be expanded descriptively by better understanding what makes mentors more effective. Simply put, effective mentorship requires effective mentors. What makes a mentor good has been a focus of mentoring scholarship. For example, Hund et al. [16] found that effective mentors in STEM doctoral programs are patient, honest, communicative, empathetic, flexible, respectful, and good listeners. Others found that personality matters, adding attributes such as smart, caring, and balanced. Effective mentors utilize these characteristics to build strong relationships signaling their investment in the mentee. In contrast, other studies looked at failed mentor relationships reporting that ineffective mentors are characterized as possessing limited communication skills, commitment, and experience [5].

Effective mentors also appreciate the importance of cultural identity whether it be racial, ethnic, gender, or something found at the intersection. Culturally responsive mentors "understand their mentee's ethnic, gender, and class background and closely relate to that background" [1]. The power of ethnic, gender, and class dynamic does not rest solely or primarily in cultural matching between the mentee and the mentor but focuses more on having a sense of sharedness in terms of values, interests, and understanding of the individual within the context of society, and personal background experience [1]. Culturally responsive mentors are effective because of the intentionality toward which they approach the dynamics of culture that may affect mentoring relationships and the lived experience of the mentee. Such mentors mentally attend to issues of power and prejudice that may lead to dysfunctional mentoring relationships, especially in cross-cultural mentoring such as between White male mentors and minority and female mentees [11]. Crosscultural mentoring relationships can be challenging in many ways, including experiencing trust issues, covert racism, power struggles, paternalism, and marginalization [10] if mentors are not intentional in proactively engaging culturally responsive practices.

Just as with teaching, for some mentors mentoring comes naturally, others have to work to develop the interpersonal skills and knowledge needed to sustain a relationship through its natural ebbs and flows. Similar to teaching, faculty are not hired based on mentoring ability. Faculty are assumed to have the prerequisite skills needed for effective mentoring and often lack proper training [9] [10].

\section{Theoretical Framework}

Critical theory serves as the framework for this study. Critical theory was selected because it "examines the current structure of society, in which dominant socioeconomic groups exploit and oppress subordinate groups" [4]. "Uncovering social structures, discourses, ideologies, and epistemologies that prop up both the status quo and a variety of forms of privilege" [12] and encouraging critical dialogue and reflection were central aims of this research, which focused on understanding the social and contextual conditions of mentoring relationships in graduate STEM education. Drawing on critical theory, the researchers engaged participants in open conversations on their mentoring relationships in order to elicit critical thinking, invite sharing experiences, and promote humility, hope, and mutual trust [4].

\section{Methodology}

A qualitative research method was used to uncover and understand "how people interpret their experiences, how they construct their world views, and what meaning they attribute to their experiences" [12]. The findings presented are drawn from a larger ongoing study, a multiple embedded case study that includes various voices, such as faculty, students, and department leaders across three institutions. The findings reported are of one of the embedded cases, doctoral students at a predominately white institution (PWI). "A case study is an in-depth exploration from multiple perspectives of the complexity and uniqueness of a particular project, policy, institution, program or system in a real-life context" [15]. Accordingly, the case study research design allowed for investigating complexity and nuances of mentoring relationships. The research question that guided this study was as follows: What are the perceptions of STEM doctoral students about their mentoring relationships with STEM faculty?

Data collection included focus groups and individual interviews. The goal of the focus groups and individual interviews was to gain insights into experiences and perspectives of STEM doctoral students. Each focus group lasted about 60 to 90 minutes and was conducted with the doctoral students at large from various STEM departments. Twenty-five students volunteered to be part of four focus groups. Also, nine underrepresented minority students agreed to semi-structured interviews that lasted between 45 to 90 minutes. The informed consent forms explained the 
purpose of the study and confidentiality measures and were collected before the data collection process began. The conversations in the focus groups and individual interviews were audio recorded and transcribed. Memo writing occurred as well and aimed to capture nonverbal reactions during the interview and offered more insights into the analysis [15].

Study limitations are largely consistent with the selected qualitative research approach: sample size, participant bias, researcher bias, as well as duration and location of the study. The limited number of participants, and participants studying in one state in the southeastern United States may mean the findings are not generalizable to STEM education in the whole country due to regional differences and state policies governing STEM programs. However, findings from qualitative research are not meant to be generalizable but the work, by providing rich detailed description, is intended to be transferable. The research also recognizes that the participants and researchers may bring various perspectives, experiences, and possible biases into the study. We documented our reflections in researcher journals throughout the study and provided participants with a safe space for critical dialogue and reflection.

\section{Analysis}

Data from the focus groups and interviews was analyzed using an inductive process, constant comparative method [8]. The analysis started by looking for raw words, then codes, leading to the development of common themes. The analysis process involved identifying words and phrases and organizing them into meaningful categories then into thematic clusters. The data investigation followed a cyclical process that proceeded from general to more specific analysis and conclusions [15].

\section{Findings}

The findings from both the focus groups and individual interviews revealed the feelings and perceptions of ineffective faculty doctoral mentoring held by doctoral students. The researchers identified cracks in the mentoring process that centered on a lack of emotional, social, and cultural inclusion in STEM doctoral mentoring relationships. Mentorships were characterized by feelings of negligence, being misunderstood, and marginalization.

\subsection{Negligence}

Negligence was a major theme constructed from the focus group data. Students expressed that the mentors used them for their research purposes, asking students to deliver their work without engaging a research process that was mutually beneficial. Students added that their goals and aspirations were overlooked, and they were treated like assembly line workers. The mentor's research projects were priority. Their needs were not prioritized. For example, a male participant in the focus group explained,

I think an important part of being a mentor is it's different from being like a manager or just a boss where they just tell you what to work on and how to manage your work. It's more like they need to understand what your goals are and help you to develop the skills. They understand how they can help you reach those goals or help you to understand how you can reach those goals. So, it's really about putting the mentee first and making sure that their goals are met.

Consistent with that sentiment, students also emphasized that mentoring should go beyond working on research, publications, or coursework guidance. For example, a female student discussed how her mentor failed to attend to all her needs. She hoped for a more holistic approach.

But I would not say that she's mentored me on that holistic level as I've been thinking about. I am not sure if that is my fault in my ... I wouldn't say necessarily reluctance, but the fact that I haven't been as honest or vulnerable with where I am going forward. But in terms of advising, she's been great helping me move forward in the program. It's absolutely wonderful. When it comes down to the mentor and thinking about it this way, I would say that I don't have a mentor at this point.

This sentiment highlighted a recurring pattern in the data; mentors engaged in advising more than mentoring. Mentors tended to provide academic guidance but did not provide the socio-emotional support required to engage in building stronger holistic mentoring relationships. The STEM doctoral student participants lacked connection with their mentors as evidenced by receiving little time and support from their mentors. One student explained that the substance of the relationship with his mentor rotated around scientific work and that his mentor did not 
engage in conversation about the student's life and heritage, depriving the mentorship of genuine connection.

\begin{abstract}
He or she never really asked me much about the details, cultural stuff. I think being able to establish a connection outside of just science is important. He or she just doesn't have much of a connection, I don't really have that one-on-one connection with her or opportunity to talk to her.
\end{abstract}

Another student, an underrepresented minority male student, described his relationship with a mentor as one that lacked genuine investment which deepened his feeling of alienation. He commented,

As far as my race is concerned, I get the sense that he goes out of his way to wish me happy MLK day, but other than that he doesn't really bring it up and that's because he knows the kind of person I am. I don't see a lot of people here that I identify with and understand where I'm coming from.

Students also explained that they experienced tensions and challenges because their mentors were not intentional in the mentorship. While they felt like their mentors checked on them perfunctorily, the students did not feel like their mentors engaged in intentional mentoring with them, leaving them confused about expectations and tasks. One student explained in the focus group that the mentor did not communicate with him enough during their mentoring process, and he was unclear about what needed to be done.

What really affects the quality of whatever kind of relationship that you're in. ... if stuff is ambiguous in a meeting, after the meeting it's going to be a 100 times, and it's not going to be good. And so you can't have a run in your office, check in, have a 30 second conversation, and leave, and call that a mentorship. It has to be intentional.

\subsection{Misunderstood}

Feeling neglected was a common experience across the focus groups which included underrepresented minority students as well as majority culture students, but feelings of being misunderstood were particularly salient for underrepresented minority students. Mentors were described as individuals who did understand where they came from, and as people who could not relate to their backgrounds and needs. For instance, one URM male student mentioned during the individual interview that his mentor was oblivious to certain challenges he experienced in the department.

I am black, and he can't necessarily
relate to those things. If I have
certain issues, I can't necessarily go
to him, and him understand ... I can
go to him and tell him like "Oh my
gosh, this happened" and he would
listen, but that doesn't necessarily
mean that he would respond in a
way of knowing because didn't go
through the same things himself.

Black students spoke of how stereotype threat infiltrated their learning experiences. The stereotype threat results when students consciously or unconsciously feel at risk of confirming an externally imposed stereotype. Psychological weight negatively affected their relationships with their mentors and their self-esteem. During the individual interview, one Black female explained her feelings of intimidation in the predominantly White male STEM environment.

Sometimes not understanding the
idea of possibly... well, having a lot
of self-doubt about oneself, the
ability of the student as a person,
which I think comes around from
being in an environment where you
don't see a lot of people who look
like you. You're afraid that if you say
something, it's not going to sound
right. Then you get put into a
category or you get you put into a
stereotype, or something like that. I
don't think she or he [my mentor]
realized that's a factor.

Because underrepresented minority students were misunderstood by faculty mentors, it was difficult for underrepresented minority students to effectively advocate for their needs. Underrepresented minority students expressed that they attempted to talk to their 
mentors about their experiences and challenges in doctoral STEM programs, reaching out for help to resolve some issues, but their mentors were unresponsive to their requests. A Black male described his mentor as unsupportive when he did not take action in helping him resolve an issue he experienced with discrimination in the department.

\section{Then he was like, "Well you know, you can't help ignorant people." And I was like, "Yes, I'm aware of that. I've been told that my whole life." I said, "I wasn't telling that to you so you can kinda put a bandaid over it, I'm making you aware of the situation and that I felt uncomfortable. And I know you have ties with the people who run this, this happened to me before, so maybe you could reach out to them and they could put out whatever about making sure that you're respectful of all walks of life". He didn't take it that far, it's more of like, "I'm sorry. These things unfortunately happen." So that's when I needed you to like, be an ally. I needed you to use your power.}

Being misunderstood occurred at two levels. Underrepresented minority students perceived that faculty mentors did not believe their mentors could relate to their backgrounds and needs, and their mentors could not understand the potential impact on their learning experiences.

\subsection{Marginalization}

A final theme cultivated from the data was marginalization. Marginalization resulted from isolation and being seen as incompetent. Social and cultural isolation in the doctoral departments was a common experience of the underrepresented minority student participants. URM students frequently mentioned that they did not have faculty who looked like them, and the students who dominated their academic departments were overwhelmingly White and male. These experiences made them invisible. For example, one underrepresented minority student said she felt alone in the program because of the duality of being a Black female.

\footnotetext{
I don't see a lot of people here that I identify with and understand where I'm coming from, so I don't feel
}

super comfortable. Makes me feel excluded. I think always being looked at as someone who doesn't belong or that's how Ifeel. Ifeel like everyone looks at me differently than everyone else.

Underrepresented minority students also commented about being referred to as incompetent in their programs. The attitudes and practices of faculty mentors were biased, and they held deficit views on diverse students, perceiving them as less qualified than their White peers. A clear instance occurred when a Black student shared comments made by his mentor.

He's made numerous comments to
me about not being smart enough to
be here, that was based on
stereotypes. And then there's the
idea of, well if I voice my opinion
when something like this happens to
whoever says it to me, then instead
of the person who said it getting
reprimanded or getting in trouble,
it's gonna be me for expressing how
Ifelt.

Women students also voiced concerns about experiencing prejudiced behavior. They were frank about the hostile attitudes they experienced from faculty mentors and other faculty in their academic departments. Sexism was also blatantly displayed in the actions of faculty mentors. One White student recalled an experience related to sexism.

She's accusing this faculty member of just blatant sexism. And, if you look at his lab, this committee member, it's all white males. I've heard it from them too, this person treats them like crap.

Faculty mentor behavior and language both overtly and covertly sent messages of belittlement to URM students and female students. These behaviors and language choices reflected biased understandings and contributed to their marginalization.

\section{Discussion}

An analysis of the data revealed the existence of cracks in STEM doctoral mentorship. Cracks formed due to lack of social, cultural, and emotional connections between faculty mentors and their doctoral students. Faculty doctoral mentors should 
consider how to better nurture and meet the needs of STEM doctoral students. Key findings echo other scholarship on mentoring. The theme of marginalization highlights the critical role of social connections. Underrepresented minority and female students, especially, expressed feelings of disempowerment that affected their sense of belonging as well as self-esteem, confidence, confirming research that emphasizes the importance of effective mentoring to boost diverse students' confidence and persistence [6]. Female students specifically talked about experiencing sexism that contributed to feelings of frustration and alienation. Connections are also needed culturally. Doctoral students mentioned that their mentors did not relate to their unique needs and did not understand their backgrounds. When faculty mentors fail to attend to those unique needs, STEM doctoral students experience neglect and emotional disconnections. Similar to Syed [17], this study shows that more tailored mentoring approaches should be put in place at the STEM graduate programs. Further findings supported research that asserts that stereotyping and misconceptions experienced by underrepresented minority students during the mentoring process have a negative influence on STEM doctoral experience, contributing to feelings of being both misunderstood and neglected. Moving mentors beyond a mindset that their only responsibility is to provide scientific guidance is key to improving the quality and effectiveness of faculty doctoral mentorships. In general, this research study confirmed the criticality of offering both instrumental and psychosocial mentoring to doctoral STEM students, so they feel accepted, appreciated, and motivated in doctoral STEM programs [20].

The findings, thus, point to the importance of mentoring training. Mentor training should specifically address the challenges posed by crosscultural mentoring relationships to help faculty mentors appreciate how prejudice, power struggles, and marginalization [10] [19] may insidiously surface in mentorship. Mentor training should also address the unique experiences of women and underrepresented minority students [7]. Due to minimal diversity within STEM faculty, a matched-background mentor process might not be possible, thus, providing the culturally responsive mentoring training is vital to help faculty gain the necessary skills, knowledge, and attitudes to mentor underrepresented minority and female students. Collectively the findings indicate the significance of emotional and cultural inclusion in mentoring relationships and adds to the existing body of literature highlighting the criticality of transforming mentoring relationships in the STEM doctoral programs in order to create a more inclusive learning environment.

\section{Conclusion}

This study adds to the body of research by emphasizing the criticality of listening to students' voices in order to understand how to improve mentoring in higher education by providing a more nuanced understanding of how doctoral students feel about their mentoring relationships in the STEM academic environment. It is telling that more negative than positive descriptors about mentoring experiences were shared. Findings can inform professional development for current and future mentors in STEM fields helping faculty STEM doctoral mentors seal the cracks created by neglect, being misunderstood, and marginalization. This research study provides information useful to enhance mentoring quality and effectiveness, especially for underrepresented minority and female students in doctoral STEM programs.

\section{References}

[1] Atkins, K., Dougan, B.M., and Dromgold-Sermen, M.S. "Looking at Myself in the Future": how mentoring shapes scientific identity for STEM students from underrepresented groups. IJ STEM Ed 7, 42 (2020). https://doi.org/10.1186/s40594-02000242-3.

[2] Dahlvig, Jolyn. "Mentoring of African American Students at a Predominantly White Institution (PWI)." Christian Higher Education 9, no. 5 (October 5, 2010): 369-395.

[3] Deborah Gross, Ellen Iverson, Gudrun Willett, and Cathryn Manduca. "Broadening Access to Science with Support for the Whole Student in a Residential Liberal Arts College Environment." Journal of college science teaching 44, no. 4 (March 1, 2015): 99-107.

[4] DeMarrais, Kathleen Bennett., and Margaret Diane. LeCompte. The Way Schools Work: a Sociological Analysis of Education 2nd ed. White Plains, N.Y: Longman, 1995.

[5] Eby, McManus. "The Protege's Perspective Regarding Negative Mentoring Experiences: The Development of a Taxonomy." Journal of vocational behavior 57, no. 1 (August 2000): 1-21.

[6] Estrada, Hernandez. "A Longitudinal Study of How Quality Mentorship and Research Experience Integrate Underrepresented Minorities into STEM Careers." CBE life sciences education 17, no. 1 (2018): ar9-. 
[7] Feldman, Mitchell D, Patricia A Arean, Sally J Marshall, Mark Lovett, and Patricia O'Sullivan. "Does Mentoring Matter: Results from a Survey of Faculty Mentees at a Large Health Sciences University." Medical education online 15, no. 1 (2010): 5063-8.

[8] Glaser, Barney G., and Anselm L. Strauss. The Discovery of Grounded Theory: Strategies for Qualitative Research Chicago: Aldine Pub. Co., 1967.

[9] Hughes, Cayce C, Kristen Schilt, Bridget K Gorman, and Jenifer L Bratter. "Framing the Faculty Gender Gap: A View from STEM Doctoral Students: Framing the Faculty Gender Gap." Gender, work, and organization 24, no. 4 (July 2017): 398-416.

[10] Hund, Amanda K, Amber C Churchill, Akasha M Faist, Caroline A Havrilla, Sierra M Love Stowell, Helen F McCreery, Julienne Ng, Cheryl A Pinzone, and Elizabeth S. C Scordato. "Transforming Mentorship in STEM by Training Scientists to Be Better Leaders." Ecology and evolution 8, no. 20 (2018): 9962-9974.

[11] Lechuga, Vicente M. "Faculty-Graduate Student Mentoring Relationships: Mentors' Perceived Roles and Responsibilities." Higher education 62, no. 6 (2011): 757-771.

[12] McLaren, Peter, and Joe L. Kincheloe. Critical Pedagogy: Where Are We Now? New York: Peter Lang, 2007.

[13] Merriam, Sharan B., and Elizabeth J. Tisdell. Qualitative Research: A Guide to Design and Implementation Fourth edition. San Francisco, CA: Jossey-Bass, 2017.

[14] National Science Foundation, National Center for Science and Engineering Statistics. (2016). Doctorates awarded to U.S. citizens and permanent residents, by sex, field, ethnicity, and race: 2016. (NSF 9-3040 [Table 7-8]. Arlington, VA: Available at https://ncses.nsf.gov/pubs/nsf19304/data.

[15] Ravitch, S., and Carl, N. (2016). Qualitative research: Bridging the conceptual, theoretical, and methodological. Sage.

[16] Simons, Helen. Case Study Research in Practice. Los Angeles: SAGE, 2009.

[17] Syed, Goza. "Individual Differences in Preferences for Matched-Ethnic Mentors Among High-Achieving Ethnically Diverse Adolescents in
STEM." Child development 83, no. 3 (May 1, 2012): 896-910.

[18] Tabbye Chavous, Seanna Leath, and Raúl Gámez. "Climate, Mentoring, and Persistence Among Underrepresented STEM Doctoral Students" Higher Education Today (June 25, 2018).

[19] Tenenbaum, Harriet R, Faye J Crosby, and Melissa D Gliner. "Mentoring Relationships in Graduate School." Journal of vocational behavior 59, no. 3 (December 2001): 326-341.

[20] Wheeless, Blaser. "Mentoring of Graduate Students In Stem: Perceptions And Outcomes." In Association for Engineering Education - Engineering Library Division Papers, 12.1059.1-. Atlanta: American Society for Engineering Education-ASEE, 2007.

\section{Acknowledgements}

This material is based upon work supported by the National Science Foundation under Grant Nos. 1820536, 182058, and 1820582. Any opinions, findings, and conclusions or recommendations expressed in this material are those of the authors and do not necessarily reflect the views of the National Science Foundation. 